\title{
Eurasian Colorectal Technologies Association (ECTA) Governing Council meeting in Moscow, April 2012
}

\author{
M. Pescatori
}

Published online: 16 May 2012

(C) Springer-Verlag 2012

A meeting of the ECTA Governing Council took place in Moscow on 6 April 2012, during the 6th congress of the Russian School of Colorectal Surgery, chaired by Professor Tsarkov (Russia), European Vice President of the ECTA. The meeting was attended by J. Korcek (Slovakia), General Secretary; K. Maeda (Japan) and Y. Panis (France), Councilors; B. Bashankaev (Russia), Co-chairman of the Training Young Surgeons Committee; and M. Pescatori (Italy), Honorary President. Several new members from Kazakhstan, Armenia, Serbia, Italy, and Ukraine joined the Association, whose aims are to encourage the correct use of innovations and to foster relationships between European and Asian colorectal surgeons. Dr. Mladen Janic (janic57@gmail.com) proposed attendance at his hospital for surgical training. Prof. Tsarkov suggested hosting the 2015 Biennial Meeting of the ECTA in Moscow, and the council accepted his proposal with enthusiasm. The next 2013 meeting will be held in Singapore and chaired by F. Seow-Choen. The two previous meetings had been perfectly organized by J.P. Wang and M. Morino. ECTA members receive the official journal Techniques in Coloproctology and may attend free courses in more than 10 outstanding institutions in Eurasia, among them the ones directed by P. Tsarkov in Moscow and Y. Panis in Paris, both devoted to laparoscopic colorectal surgery. The website of the Association is www.ectamed.org, run by A. Arezzo in Turin. Professor Aghavelian (alexdoc2008@gmail.com) invited ECTA members to attend the surgical meeting in Yerevan (Armenia) in May 2013. The new ECTA council will be elected in Singapore in 2013. For further

M. Pescatori $(\bowtie)$

Ars Medica Hospital and La Sapienza University, Rome, Italy e-mail: ucpclub@virgilio.it

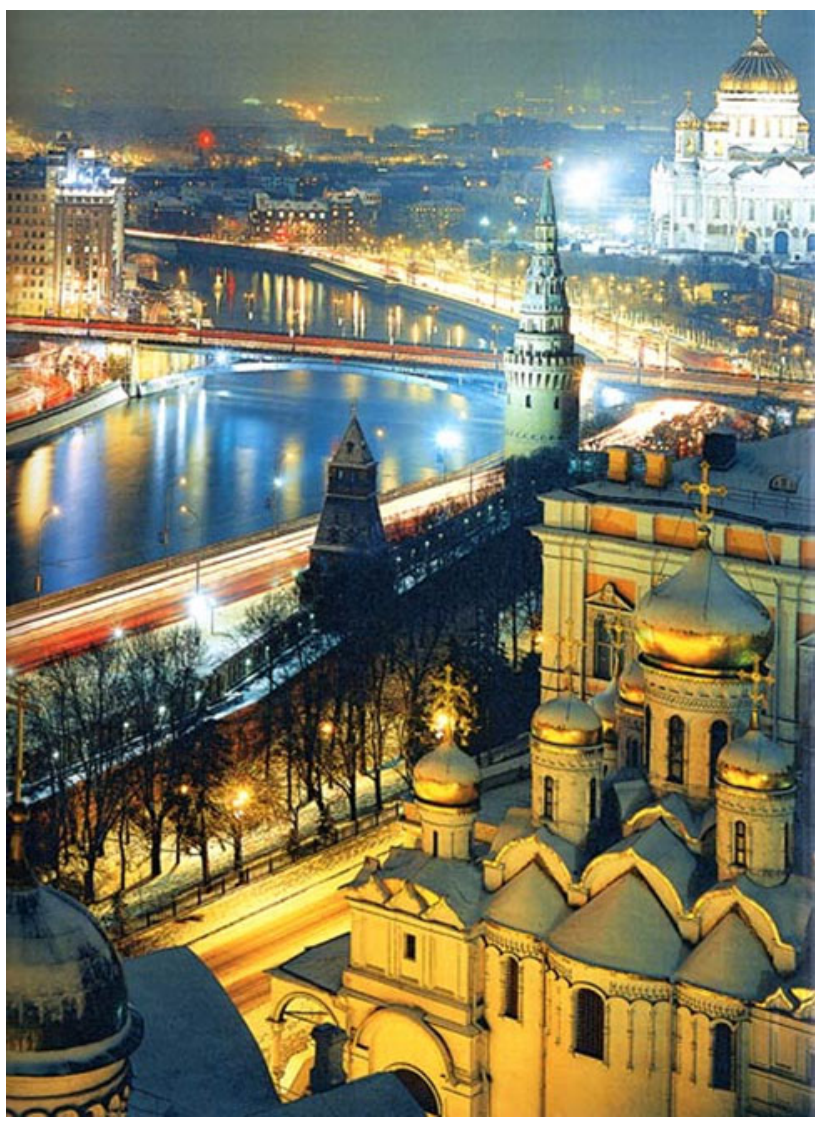

information, please contact andrea.bondurri@voila.fr. To receive the journal, please contact patrizia.bianchi@ springer.com. If you are interested in founding ECTA branches in the Eurasian countries, please contact seowchoen@colorectalcentre.com. For information about the ECTA courses that are free for members, please contact caterinadebono@live.it. 